\title{
Perceived Poll Bias and Inference of Biased Poll Impact in the 2010 U.S. Midterm Elections: Media Performance in the Eyes of the Beholder
}

\author{
Ran Wei ${ }^{1, *}$ and Ven-Hwei Lo ${ }^{2}$ \\ ${ }^{I}$ School of Journalism \& Mass Communications, University of South Carolina, Columbia, SC 29208, USA; ${ }^{2}$ School of \\ Journalism \& Communication, Chinese University of Hong Kong, Shatin, Hong Kong
}

\begin{abstract}
This study examines the role of perceptions of opinion polls in assessing media performance in the 2010 midterm elections using data collected in a southern state. Results show strong hostile media effect in viewing the favorability of the polls and the third-person effect in assessing the impact of the polls on others and oneself. Moreover, results indicate that the influence of hostile polls on the perceived effect of these polls on oneself relative to others was mediated by poll exposure. Perception of hostile polls was found to be negatively related to poll exposure. The hotile perception indirectly affects perceived effects of polls on oneself and others, which in turn directly affects support for restrictions of election polls. The theretical and practical implications of the findings are discussed.
\end{abstract}

Keywords: Third-person effect, hostile media effect, election polls, exposure, selective exposure, midterm elections.

\section{INTRODUCTION}

In constructing social reality in a mass-mediated world, people have the tendency to view media messages in different ways. They tend to believe that the message may be biased or slanted in favor of others and against them, and they perceive the biased message as having a differential influence on themselves in relation to others with themselves being immune from the influence. The first tendency is known as the hostile media effect, while the second is called the third-person effect. In the robust research paradigm of the influence of presumed media influence in mass communication (Gunther \& Storey, 2003), these two phenomena underscore the critical role of perceptions in interpreting media content and inferring its impact on audience.

More importantly, these perceptions affect audience behavioral intentions and actual behavior. Numerous thirdperson effect studies show that those who believe that others are more affected by negative or persuasive media messages than they are will consistently support restrictions on such messages (Xu \& Gazebach, 2008). Similarly, past research of the hostile media effect demonstrates that individuals who form the opinion that the message is biased against them are inclined to take action to punish the media for producing the biased message (Gunther, 1991). The research suggests that presumed media effects are real media effects (Perloff, 2002; Tal-Or, Tsfati \& Gunther, 2009).

In a study of the hostile media effect, Gunther and Schmitt (2004) suggested that the third-person effect and biased media perceptions are related because both concern perceptions of media performance. They suggested that anticipated third-person effects of controversial or negative

*Address correspondence to this author at the School of Journalism \& Mass Communications, University of South Carolina, Columbia, SC 29208, USA; Tel: (803) 777-5762; Fax: (803) 777-4103; E-mail: wei2@mailbox.sc.edu media messages would induce hostile media perceptions. To examine the role of perceptions of opinion polls, this study applies the third-person effect and hostile media effect frameworks in the context of polls in the 2010 midterm elections in a predominantly Republican southern state. Our study is unique in two ways: First, past research exploring the perceived influence of polls focused on presidential elections; the context of our study is about perceived effects of polls in off-year elections, to which voters tend to pay less attention than presidential elections. Under these circumstances, we will be able to test the role of exposure to polls in mediating the third-person effect and the hostile media effect. In doing so, a path model approach will be used to delineate the direct and indirect relationships between the third-person effect and hostile media perception. Second, we focused on a Republican state in the south with polls favoring Republican candidates because it allows us to draw on the hostile media literature to examine the relative hostile media effect by comparing the perceptions of polls in favor of Republican candidates against Democratic candidates.

Findings will shed light on the process of how hostile perception of media messages affects the appraisals of the effects of the messages when exposure is taken into consideration. We anticipate that people's perception of hostile media will likely affect their judgments on the effect of the polls on others relative to themselves. Perception of hostile polls in the 2010 midterm elections has the promise to offer a cognitive explanation to the widely demonstrated but less explained third-person effect.

\section{THEORETICAL FRAMEWORKS AND HYPOTHE- SES}

\section{The Third-Person Effect}

In appraising the impact of media messages, people have the propensity to believe that others are more likely to be 
impacted than themselves (Davison, 1983). The biased perception of media effects, known as third-person perception, has been examined in more than 100 studies (Paul, Salwen, \& Dupagne, 2000; Sun, Pan, \& Shen, 2008; Tak-Or et al., 2009). Focusing on campaign messages in the 1996 presidential election, Salwen (1998) reported that individuals perceived a greater media influence on people other than themselves. Similar results were reported in the 1993 Australian federal election (Duck, Hogg, and Terry 1995): respondents judged others as more influenced by the election campaign than they were. The third-person perception of campaign messages in the 2004 U.S. Presidential election was found to be larger for the outgroup than the ingroup, among Republicans (Hofner \& Rehkoff, 2011).

Treating opinion polls as a type of distinctive political message, Pan, Abisaid, Paek, Sun, and Houden (2005) also documented evidence in support of the third-person perception. Consistent results were reported in other studies that found that respondents perceived the effect of election polls to be greater on other voters than on themselves (Lavrakas, Presser, \& Lee, 2010; Price \& Stroud, 2005; Wei et al., 2011; Wei, Lo, \& Lu, 2010). In examining voters' appraisal of the impact of polls, we hypothesize that the baseline third-person perception will exist in the 2010 midterm elections:

H1: Respondents will perceive polls in the 2010 midterm elections to have a greater impact on others than on themselves.

\section{Hostile Media Perception}

While the third-person effect research focuses on perceptions of media impact on oneself relative to others, another stream of media perception research concentrates on people's perceptions of media bias or slant in a certain direction. People who are highly involved in a controversial issue (namely partisans) are likely to perceive media coverage of the issue as portrayed with a biased slant, even though people not involved in the issue (namely nonpartisans) would view the same coverage as basically unbiased. Vallone, Ross, and Lepper (1985) called it hostile media perception. Their experimental study of television news reports of the 1982 Beirut massacre showed that both pro-Arab and pro-Israeli subjects interpreted the same stories as hostile to their personal opinion. Perloff (1989) replicated the study and reported consistent findings.

Numerous studies reported support of the hostile media effect on issues such as genetically modified food (Chia et al., 2007; Gunther \& Schmitt, 2004; Giner-Sorolla \& Chaiken, 1994; Matheson \& Dursun, 2001), news coverage of presidential elections (Dalton, Beck, \& Huckfeldt, 1998), and broadcast news (Arpan \& Raney, 2003; Morris, 2007). Coe et al. (2008) examined perceptions of bias between partisan groups across three different news sources of political information which represent different ideological orientations: Cable News Network (CNN), Fox News Channel, and Comedy Central's The Daily Show. They found that subjects were more likely to see bias in Fox and Comedy Central programs than in CNN. Moreover, liberals were found to perceive less bias in The Daily Show but more bias in the Fox News program; interestingly, conservatives' perceptions were the opposite.
In the context of political campaigns, Gardikiotis (2008) reported that supporters of political parties perceived the media campaign to be unfair against their party. However, low party identifiers perceived the same campaign as more or less fair. According to Hoffner and Rehkoff (2011), hostile news perceptions were greater among Republicans in the 2004 U.S. presidential election.

Recent hostile media perception research suggests that the phenomenon exists in circumstances in which the highly issue-involved, the general public, and the news slant unequivocally favor one side of an issue. In these circumstances, the general public on both sides will perceive the message to be biased in the same direction, but they will perceive the message as more unfavorable toward their position than other side. Gunther and Chia (2001) characterized it as the relative hostile media phenomenon. Past research (Coe et al., 2008; Gunther, Christen, Liebhart, \& Chia, 2001; Gunther \& Christen, 2002;) found supporting evidence.

Recent studies (e.g., Wei et al., 2011) expanded the domain of the relative hostile media effect to election campaigns. Focusing on the 2008 presidential election, they explored whether the relative hostile media phenomenon existed in terms of respondents' perceptions of polls tracking the two candidates. Almost all polls indicated that the Democratic candidate Barack Obama led the campaign against the Republican candidate John McCain. Most voters would be aware that the polls favored Obama and disfavored John McCain. Under such circumstances, as the relative hostile media effect prescribes, supporters of the two candidates would see and evaluate the polls differently. Findings showed that supporters of Obama were less likely than opponents of Obama to perceive that polls were biased in favor of Obama and that polls disfavored McCain; supporters of McCain were less likely than opponents of McCain to perceive that polls were biased in favor of McCain and that polls disfavored Obama. Wei et al. (2011) concluded that, despite the fact that polls consistently indicated the lead of one camp's candidate, supporters on both sides still believed the polls to be hostile to their own side relative to the way the other group perceived it.

The 2010 midterm elections provided an appropriate context to explore the hostile media effect in midterm elections featuring state-level races for Congressional seats because polls predicted a likely pendulum swing, allowing Republicans to win back the majority of the House (a gain of 55-64 seats) and the Senate (a gain of 10 seats). In the week leading to Election Day, Gallup polls (Gallup, 2010) predicted a Republican win by large margins over Democrats in both a low turnout scenario (55\% vs. $40 \%)$ and a high turnout scenario (52\% vs. $42 \%)$. South Carolina reflected national trends. In the Senate race, polls showed the Republican incumbent, James DeMint had a 42 point advantage and led his Democratic opponent, Alvin Green, $61.48 \%$ to $27.65 \%$. Among the six House races, five Republican candidates led by a large margin in the polls. Thus, polls in the midterm elections in South Carolina provided an opportunity to examine the relative hostile media effect.

Specifically, we anticipate that supporters of Republican candidates will be less likely than those who do not support 
the Republican candidates to view that polls in the 2010 midterm elections favored Republicans and disfavored Democrats. On the other hand, supporters of Democratic candidates will be more likely than non-supports to perceive that election polls favored Republicans and disfavored Democrats. Therefore, we hypothesize that:

H2a: Republican supporters will be more likely than Democratic supporters to believe that polls in the 2010 midterm elections are biased against Republican candidates.

H2b: Democratic supporters will be more likely than Republican supporters to believe that polls in the 2010 midterm elections are biased against Democratic candidates.

\section{Media Exposure as Antecedent of Media Perceptions}

Past research suggests that self-other difference in perceptions of media influence is affected by social structural factors and media use patterns (Rucinski \& Salman, 1990). Salwen (1998, p. 264) argued that media exposure may "amplify" the third-person perceptual gap"the more exposure to media messages, the greater the selfother perceptual difference in assessing the effect of the messages. Eveland et al. (1999) found that perceived likelihood of exposure was a significant predictor of perceived impact of violent rap music on others. According to McLeod, Detenber, and Eveland (2001), higher level of exposure leads to greater perceived effects because the estimates of effect on others were likely based on a "magic bullet" schema of powerful media effects.

Previous research (Gunther \& Storey, 2003; Rusinski \& Salmon, 1990) reported that TV viewing was positively related to perceived effects of political messages on the self, while greater newspaper exposure, exposure to radio drama, and reading fashion magazines were positively associated with greater perceived effects on others. Other studies (Wei et al., 2008) suggested that exposure to specific media content is a stronger predictor of the third-person perception than general media exposure. Wei and Lo (2007) found exposure to political attack ads to be a stronger predictor of the perceived harms of such ads on oneself and on others than general media use, including newspaper reading, television viewing, and surfing the Internet.

In the context of this study, the polls concerning the 2010 midterm elections in a single state are unlike those in presidential elections, which usually garner a high level of voter attention. To test exposure as a predictor of the thirdperson effect in an off-year election, we hypothesize that:

H3a: Exposure to polls in the 2010 midterm elections will be significantly and positively related to perceived effects of such polls on oneself.

$\mathrm{H} 3 \mathrm{~b}$ : Exposure to polls the 2010 midterm elections will be significantly and positively related to perceived effects of such polls on others.

One of the main concerns about the hostile media effect is that it may affect media exposure largely because people are less likely to use or pay attention to news media that they perceive as biased against them or untrustworthy (Johnson \& Kaye, 1998; Lo, 2004). To put it in another way, partisans tend to selectively expose themselves to media or messages that are ideologically congenial. They shun media believed to be biased against them.
In lab experiments, Arceneaux, Johnson, and Murphy (2010) found that the hostile media effect was significantly moderated by selective exposure. They argued that selective exposure substantially blunts the hostile media effect. Mende (2008) reported similar findings in the context of a controversial urban construction project. She found that partisans read more content consistent with their own opinion than content that was opposite to their view. The experiments demonstrated a significant reduction of perceived hostile media bias when subjects were allowed to expose themselves to messages of their choice.

Comparing political content on late-night comedy shows with mainstream broadcast news, Arpan et al. (2009) examined perceptions of media bias and found the hostile media effect across five comedy shows. Exposure to news content was found to moderate the effect of political partisanship on perceptions of bias in both news and comedy shows. Therefore, we expect that perception of hostile polls will be negatively related to exposure to such polls in the 2010 midterm elections. Specifically,

H4: Perception of hostile polls in the 2010 midterm elections will be significantly but negatively related to exposure to such polls.

\section{Behavior Consequence of Media Perceptions}

Research on media perceptions, whether concerned with the perceived influence of media messages or the perceived bias of hostile media, is robust largely because people who hold the perceptions are likely to act on them. People may engage in rectifying behaviors to restrict negative media messages (Sun et al., 2008). A large number of third-person effect studies show that those who believed others were more affected by media messages than themselves would support restrictions of such messages for the sake of protecting others (Lo \& Wei, 2002; McLeod et al., 1997; Youn, Faber, \& Shah, 2000). Among the studies that focused on the presumed effect of polls from the third-person effect perspective, Salwen (1998) confirmed that third-person perception led to support for restrictions on campaign messages in the 1996 presidential election. Consistent findings are reported in Denmark's 2000 Euro referendum poll (de Vreese \& Semetko, 2002), in pre-election polls (Price and Stroud 2005), and in the 2008 presidential election (Wei et al., 2011).

Past research suggests examining the effects of perceived message influence on oneself and on others separately because of methodological issues (Lo \& Wei, 2002). A study on effects of a Holocaust-denial ad (Price, Tewksbury, \& Huang, 1998) reported that it was perceived impact on the self, not on others, that predicted opposition to publishing the ad. In the context of a presidential election in Taiwan (Wei et al., 2010), perceived negative effect of polling news on others was found to be the strongest predictor of intention to support restrictions on reports about election polls.

Similarly, past hostile media effect research demonstrates that individuals who form the opinion that the message is biased against them are inclined to take action to punish the media for producing the message. As Gunther (1991) argued, people's favorable attitudes toward media censorship often reflect their intention to penalize the media for doing harm to the subject of the negative message. Therefore, pro- 
censorship attitudes will compensate for the subject of the negative message (Chia et al., 2004). Empirical support was reported in studies involving defamatory news stories (Gunther, 1991) and sex videos (Chia et al., 2004). In the context of a presidential election, past studies (Wei et al., 2011) found that, when polled, respondents perceived that election polls were biased in favor of the candidate whom they opposed; at the same time, they perceived that the polls disfavored the candidate whom they supported. Because of this perceived bias, they would support restrictions of election polls to penalize the media and to compensate the candidate whom they supported. Hoffner and Rehkoff (2011) also found that greater perceived influence on outgroup voters (namely Republicans) was associated with stronger support for censorship of campaign messages among Democrats in a third-person effect study of the 2004 U.S. presidential election.

Drawing on the literature, we anticipate that Republican supporters who think that the pro-GOP polls will likely energize Democrat supporters and make Republican supporters complacent, or Democrat supporters who think the pro-GOP polls will have a bandwagon effect for GOP candidates, will likely support restricting the polls. Therefore, the following hypotheses concerning the behavioral aspect of media perceptions were proposed:

H5a: The perceived effects of polls in the 2010 midterm elections on oneself will be positively related to support for restrictions of such polls.

H5b: The perceived effects of polls in the 2010 midterm elections on other voters will be positively related to support for restrictions of such polls.

H6: Perceived hostile polls in the 2010 midterm elections will be positively correlated with support for restrictions of such polls.

\section{The Relationship Between Third-person Effect and Hostile Media Perception}

Finally, recent research has explored how the two phenomena regarding media perceptions are related. In assessing the hostile media perception of an article from a traditional news source vs. a student essay among supporters and opponents of genetically modified foods, Gunther and Schmitt (2004) reported the biased perception evaporated when student essay was thought to be the source. They argued that the perception of media bias was related to the reach of the message. The bias is pronounced when identical information is disseminated through the media and read by a large audience of gullible others.

The relationship between third-person effect and hostile media perception merits further attention because people's perception of messages produced by hostile media will affect their judgments on the effect of the message on the themselves and on others. Then, their behavioral intention to restrict the message originated from hostile media will be better understood. A study by Wei et al. (2011) reported a significant relationship between the two phenomena in the 2008 presidential election polls. The higher the level of bias that the voters believed polls had, the more effect the polls were perceived to have on oneself and others. It appears that people judge whether the media has any bias that is hostile to their own views or positions. The more biased and hostile the messages are perceived, the greater the harms they are believed to have on others. The findings make sense because biased polls hostile to candidates that one supports were considered to be undesirable, a fitting condition for the thirdperson perception. Accordingly,

H7: The perception of hostile polls in the 210 midterm elections will be positively related to perceived effects of election polls on others.

Because previous studies failed to illuminate how the two phenomena are related when antecedents, such as exposure, are taken into account, we attempt a path model approach in assessing the relationship between the third-person effect and the hostile media effect using polls in the 2010 midterm elections in a predominantly Republican state as the context. This context was carefully chosen because voters tend to pay less attention to off-year elections as compared to the mediahyped presidential elections.

As Fig. (1) shows, we propose that the relationship between the hostile media effect and the third-person effect concerning polls in the 2010 midterm elections will be mediated by exposure to polls. Our rationale is based on the earlier discussion (refer to H4) that hostile media perception is a negative correlate of exposure. The more media bias that is hostile against them is perceived, the less people tend to expose themselves to the hostile messages. Under this condition, hostile media perception increases, exposure diminishes, and the appraisal of such messages on oneself and others will be less pronounced. Therefore, we develop a research question to test the mediating role of exposure:

RQ1: Does exposure mediate the effects of perception of hostile polls on the third-person effect of polls in the 2010 midterm elections? If so, how?

\section{METHOD}

A probability sample was used in data collection in a predominantly Republican state, which allows us to examine the relative hostile media effect by comparing the perceptions of election polls in favor of Republican candidates relative to Democratic candidates. The sample

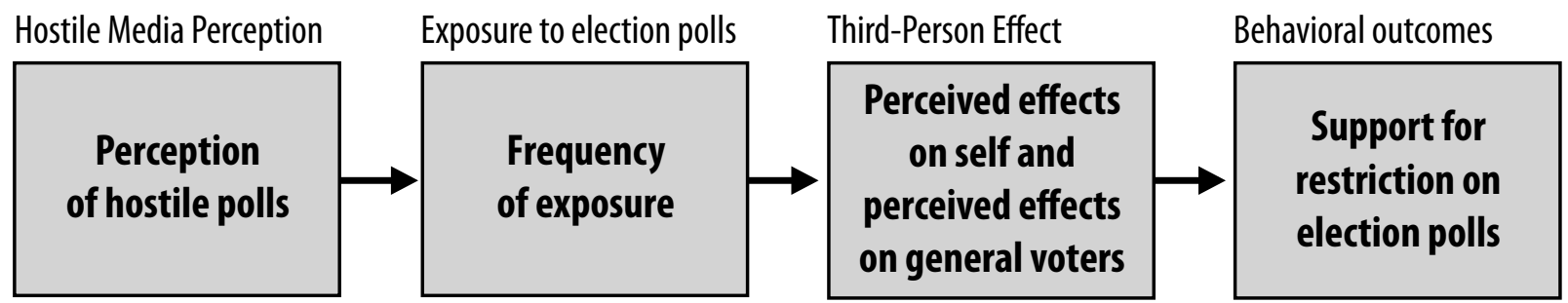

Fig. (1). Model showing how HMP becomes a behavior. 
was drawn from a public university in the southeast using a multi-step stratified strategy. The sample was stratified by size of departments; two large, seven medium, and eight small departments were selected randomly. Classes, which were stratified by large (100 or more students), medium (5099 ), and small (49 or fewer), were randomly selected next. This multi-stage sampling procedure resulted in a total of 17 classes. The total sample size was 851 students. Trained undergraduate students assisted in administering the survey two weeks before the November 2, 2010, Election Day. Participation was voluntary, no class credit was offered. Respondents were assured of anonymity and confidentiality.

Among the 851 students in the sample, 562 completed and valid surveys were collected, yielding a response rate of $66 \%$. Of the sample, $56.9 \%$ were males. The mean age was 19.94 years ( $\mathrm{SD}=2.12$, ranging from 18 to 42 ). Nearly $40 \%$ were freshmen, followed by junior $(24.2 \%)$, senior $(19.0 \%)$, sophomore $(16.5 \%)$, and graduate students $(1.1 \%)$. In terms of race, $87.0 \%$ were white, $10.4 \%$ were African-Americans, $1.8 \%$ were Hispanics, and $0.7 \%$ were Asian. With regard to party affiliation, $25.4 \%$ self-reported as strong or moderate Democrats, $21.9 \%$ as Independent, and $52.7 \%$ as strong or moderate Republicans.

\section{Operationalization}

Exposure to election polls. Respondents were requested to report how often they had seen polls of the 2010 midterm elections in (1) newspapers, (2) on television, (3) online, and (4) on blogs and social media. The scale ranged from 1 to 5 , with "1" meaning "never," "2" meaning "rarely," "3" meaning "sometimes," "4" meaning "often," and "5" meaning "all the time." Results of principal component factor analysis showed that the four items grouped in a single factor (Eigenvalue $=2.70$, accounting for $67.42 \%$ of the variance). A composite measure of exposure was developed by averaging these items $(\mathrm{M}=2.03, \mathrm{SD}=.93, \alpha=.84)$.

Perceived effects of election polls on oneself and others. Respondents were asked to rate the influence of polls on their voting decision in the 2010 midterm elections. The 5point response categories ranged from 1 ("no influence at all") to 5 ("a great deal of influence") $(\mathrm{M}=2.08, \mathrm{SD}=1.20)$. Using the same scale, respondents were asked to rate the influence of the polls on the voting decision of (1) independent voters $(\mathrm{M}=2.92, \mathrm{SD}=1.04)$, (2) Democratic voters $(\mathrm{M}=2.92, \mathrm{SD}=1.09)$, (3) Republican voters $(\mathrm{M}=$ $2.88, \mathrm{SD}=1.10)$, and $(4)$ general voters $(\mathrm{M}=3.14, \mathrm{SD}=$ .99).

Perception of hostile polls. Respondents were asked about their agreement that polls are biased against (1) the candidates that he/she supports, (2) the party that he/she supports, and (3) the issues that he/she supports. A 5-point Likert scale was used. Results of a principal component factor analysis showed that the three items grouped in a single factor (Eigenvalue $=2.45$, accounting for $81.78 \%$ of the variance). The items were averaged to create a composite measure of perception of hostile polls $(\mathrm{M}=2.90, \mathrm{SD}=.69$, $\alpha=.89$ ).

Perceived election poll bias. Respondents were first asked to rate the extent to which they agreed that election polls are biased against Democratic candidates, and treat Democratic candidates less fairly on a 5-point Likert scale.
They were then asked about their agreement whether election polls are biased against Republican candidates, and treat Republican candidates less fairly. The two items concerning Democratic candidates were added and divided by two to form a measure of perceived election polls biased against Democratic candidates $(\mathrm{M}=2.80, \mathrm{SD}=.73, \mathrm{r}=.61)$. Similarly, the two items concerning Republican candidates were averaged to form a composite measure of perceived election polls bias against Republican candidates $(\mathrm{M}=2.93$, $\mathrm{SD}=.77, \mathrm{r}=.62)$.

Support for restrictions of election polls in the media. Using a 5-point scale ranging from "1" ("very unlikely") to "5" ("very likely"), respondents were asked about the likelihood that they would take the following action to limit the impact of polls in the 2010 midterm elections: (1) sign a petition for fair media reports of election poll results, (2) boycott news organizations that reported election polls with bias, (3) support legislative action to penalize news organizations that reported election polls unfairly, and (4) support legislative action to ban unfair reports about election polls. These items were subjected to a principal component factor analysis to assess dimensionality. A single-factor solution emerged (Eigenvalue $=2.94$, accounting for $73.48 \%$ of the variance). The items were combined into a composite measure of support for restrictions on election polls in the media $(\mathrm{M}=2.18, \mathrm{SD}=1.07, \alpha=.88)$.

Personal characteristics and demographic variables included age, gender, household income, race, and political party affiliation. They were used as control variables in the regression and path analysis.

\section{RESULTS}

\section{Hypothesis-testing}

H1 predicted that respondents would perceive that polls in the 2010 midterm elections to have a greater impact on others than on themselves. Table 1 shows the results of paired t-test. The differences were all significant. H1 was supported.

$\mathrm{H} 2 \mathrm{a}$ predicted that Republican supporters would be more likely than Democratic supporters to perceive that election polls to be biased against Republican candidates. As Table 2 shows, results of a two-sample t-test showed $\mathrm{t}(419)=-4.00, p$ $<.001$ that Republican supporters were more likely to believe that election polls were biased against Republican candidates than Democratic supporters. H2a was supported. $\mathrm{H} 2 \mathrm{~b}$ predicted that Democratic supporters would be more likely than Republican supporters to perceive that election polls were biased against Republican candidates. Results of two independent-samples t-test supported H2b $[\mathrm{t}(420)=3.13$, $p<.01]$. Democratic supporters were more likely to believe that election polls were unfavorable to Democratic candidates than Republican supporters. H2b was supported.

$\mathrm{H} 3 \mathrm{a}$ predicted a positive relationship between exposure to election polls and perceived effect of such polls on the self. Exposure was significantly related to perceived effects on oneself $(r=.16, p<.001)$. It was supported. H3b predicted a positive relationship between exposure to election polls and perceived effect of such polls on others. Correlation result showed that exposure was a significant correlate of perceived effect on other voters $(r=.16, p<$ 
Table 1. Mean Estimates of Perceived Effects of Election Polls on Oneself and Others (by PartyAffiliation)

\begin{tabular}{|c|c|c|c|c|c|c|}
\hline \multicolumn{9}{|c|}{ Comparison Groups } \\
\hline Samples & $\mathbf{N}$ & Oneself & Oneself Democrats & Other Republicans & Independents & General Voters \\
\hline \hline All & 554 & $2.29(1.16)$ & $2.92(1.08)$ & $2.88(1.09)$ & $2.92(1.03)$ & $3.14(0.99)$ \\
\hline
\end{tabular}

Note: Figures in parentheses are standard deviations.

Oneself vs. other Democrats $\mathrm{t}=11.67 * * *$; Oneself vs. other Republicans $\mathrm{t}=10.42 * * *$;

Oneself vs. independents $\mathrm{t}=11.57 * * *$; Oneself vs. general voters $\mathrm{t}=15.51 * * * ; * * * \mathrm{p}<.001$.

Table 2. Mean Estimates of Perceived Election Polls Bias against Democratic and Republican Candidates (by Party Affiliation)

\begin{tabular}{|c|c|c|c|}
\hline \multirow{2}{*}{} & \multicolumn{2}{|c|}{ Perceived biased polls against } \\
\cline { 2 - 4 } & & Democratic Candidates & Republican Republicans \\
\hline Samples & $\mathbf{N}$ & Mean (S.D.) & Mean (S.D.) \\
\hline \hline Democrats & 137 & $2.96(0.77)$ & $3.03(0.49)$ \\
\hline Republicans & 285 & $2.83(0.59)$ & $-4.000^{* * *}$ \\
\hline t value & & $3.13 * *$ & \\
\hline
\end{tabular}

$* * \mathrm{p}<.01 ; * * * \mathrm{p}<.001$

.001). It was supported. H4 predicted that perception of hostile polls in the 2010 midterm elections and exposure to such polls would be negatively related. Correlation result showed that hostile perception as a significant but negative correlate of exposure $(r=-.10, p<.05)$. H4 was supported.

$\mathrm{H} 5 \mathrm{a}$ predicted that perceived effect of election polls on the self would be positively correlated with support for restrictions of such polls. It was supported by correlation result, which showed perceived effect on oneself was significantly related to support for restriction $(r=.17, p<$ $.001)$. H5b predicted that perceived effect of election polls eon others would be positively correlated with support for restrictions of such polls. As expected, perceived effect on others was significantly related to support for restriction $(r=$ $.18, p<.001)$. H5b was supported. H6 predicted that perception of hostile election would be positively correlated with support for restriction of election polls. Result of correlation showed that hostile poll perception was not a significant correlate of support $(r=.05, p>.05)$. H6 was not supported.

H7 predicted a positive relationship between perception of hostile polls in the 2010 midterm elections and perceived effect of such polls on others. The correlation between perception of hostile polls and perceived effects on others was significant $(r=.07, p<.05)$. It was supported.

\section{Path Analysis}

To address RQ1, which explored the question whether and how exposure to polls mediates the relationship between the third-person effect of polls and perception of hostility of such polls, a path analysis was performed. The path model included four regression analyses. In the first regression analysis, exposure to polls was regressed on the perception of hostile polls and the four control variables (e.g., gender, age, race, and political party affiliation). As results in Fig. (2) show, hostile perception of polls was a significant but negative predictor of exposure to polls after the influences of control variables were taken into account. This particular finding provided additional evidence to support $\mathrm{H} 4$.

In the second regression analysis, perceived effect of polls on oneself was regressed on perceived hostile polls, exposure to polls, and the four control variables. Results show that only exposure held predictive power over perceived effects on oneself after the influences of the four control variables were taken into consideration. Perception of hostile polls was not a significant predictor. Theses results provided additional evidence to support $\mathrm{H} 3 \mathrm{a}$. In the third regression analysis, perceived effect of polls on others was regressed on perception of hostile polls, exposure to polls and the four control variables. Results show that perception of hostile polls and exposure were significant predictors of perceived effect on others after controlling the influences of the four control variables. These findings provided additional support for $\mathrm{H} 3 \mathrm{~b}$ and $\mathrm{H} 7$.

The fourth regression analysis regressed the dependent variable of support for restrictions of election polls on perceived hostile polls, exposure to polls, perceived effects on oneself, perceived effects on others, and the four control variables. When the influences of these predictors were considered simultaneously, exposure, perceived effect on oneself and on others were significant predictors. However, perception of hostile polls was not a significant predictor. The results are consistent with that of $\mathrm{H} 5 \mathrm{a}, \mathrm{H} 5 \mathrm{~b}$ and $\mathrm{H} 6$.

These results indicate that the effect of perceived hostile polls on the perceived impact of polls on oneself and others as well as support for restrictions worked through exposure. Specifically, the influence of hostile media perception on the perceived effects on the self is indirect, working through exposure to election polls. The findings reveal significant paths between perception of hostile polls and exposure to such polls, between exposure and perceived effects on the self and on others, and between perceived effects on the self and on others and support for restrictions of such polls. 


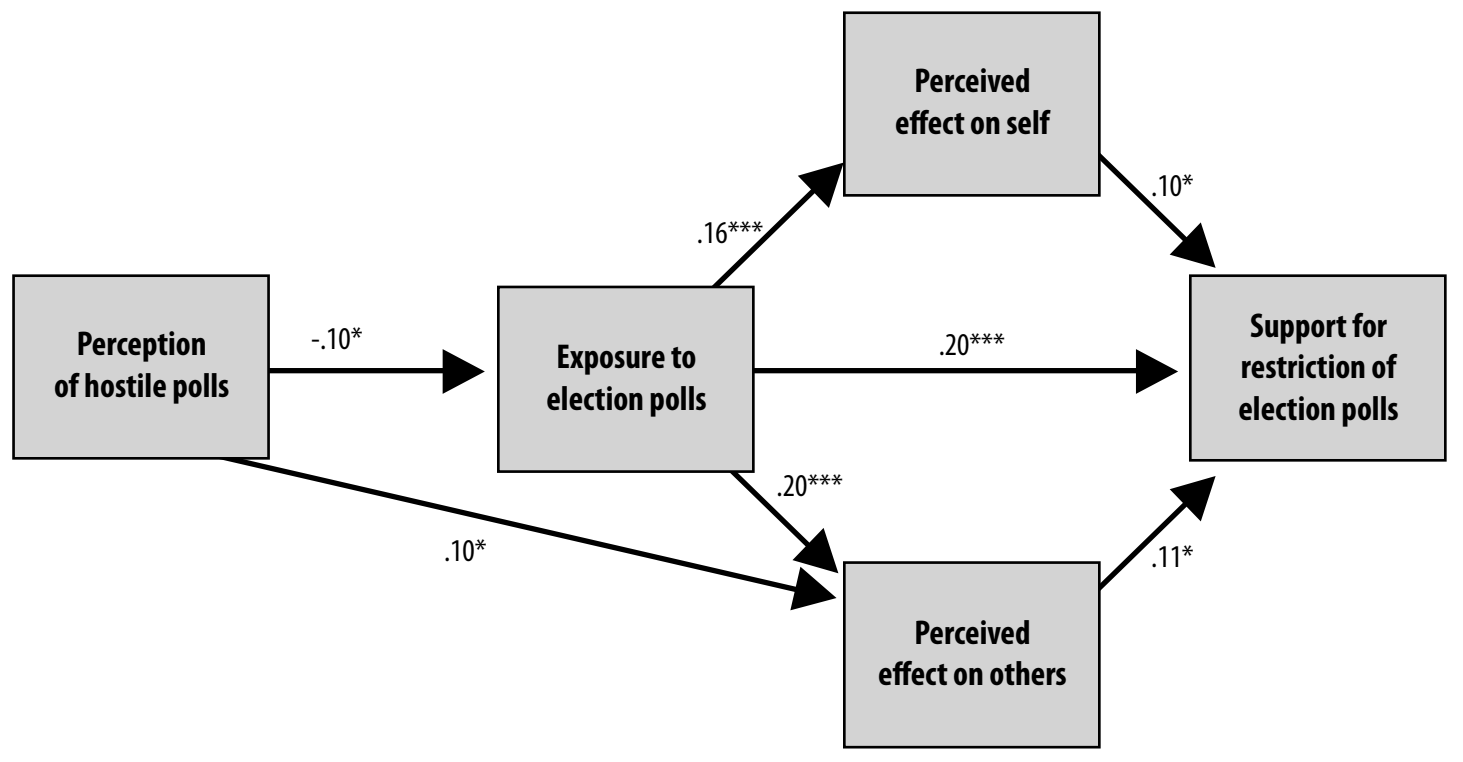

Fig. (2). Results of Path Analysis.

To assess the mediation effects, we adopted a procedure developed by Sobel (1982) that provides a direct test of an indirect effect. The Sobel test was employed because it performs well for moderate to large effect size with a large sample (Holbert \& Stephenson, 2003; Preacher \& Hayes, 2004). The mediator in our theoretical model is exposure to election polls. Thus, there is one potential mediating effect between perception of hostile polls and perceived effects of election polls on oneself. The results of the Sobel test show that the $z$ score for mediation path through exposure to election polls is $-3.09(p<.01)$. Therefore, we generated evidence in support of the proposed model that exposure to election polls is a statistically significant mediator in the relationship between perception of hostile polls and perceived effects of election polls on oneself.

Similarly, exposure to election polls is also a potential mediator in the relationship between perception of hostile polls and perceived effects of election polls on others. The results of the Sobel test indicate that the mediation path through exposure to election polls has a $z$ score of $-2.84(p<$ $.05)$. Accordingly, exposure to election polls is a significant mediator in the relationship between perception of hostile polls and perceived effects of election polls on others.

Additionally, the direct effect linking perceived hostile polls and support for restrictions of elections was .05, while the indirect effect linking exposure to polls and support for restrictions was .238 . The indirect effect is about five times greater than the direct effect. This means that the influence of perception of hostile polls on support for restrictions of such polls - the behavioral component of the third-person effect-is also mediated through exposure and perceived effects on the self and others. These results provide more evidence in support for the mediating role of exposure in assessing the influence of the hostile media effect on the third-person effect.

\section{DISCUSSION}

In viewing polls in the 2010 midterm elections, we found that the phenomenon of third-person perception and hostile meida percpetion were robust. Respondnets believed that the polls were biased against the candidates they supported. Supporters of the Republican Party were more likely to see the polls as leaning toward Democratic candidates and disfavoring Republican candidates, whileras Democratic supporters were more likely to view the same polls as leaning toward Republican candidates and disfavoring Democratic candidates. This is the case even when all the polls reported a large Republican lead. These findings are consistent with the national trend that the American electrorate is increasingly polirized (Baldassarri \& Gelman, 2008 ) and political polarization are most pronouced among informed and politically active citzens (Baldassarri \& Gelman, 2008).

We further found that exposure to polls was a major antecedent affecting the respondents' support for restriction of election polls and inferred the impact of perceived hostile polls on themselves relative to others. Exposure appears to have enhanced the third-perception effect of polls in the 2010 midterm elections. It seems to have also increased willingness to support censorship of election polls. These results are consistent with the literature as well (Arceneaux et al., 2010; Mende, 2008; Salwen, 1998).

More importantly, our findings indicate that the relationship between the hostile media effect and the thirdperson effect concerning election polls was mediated by exposure, revealing a dynamic process in which people form perceptions of media hostility and infer media impact on themselves and on others. Because people with different positions on issues tend to expose themselves selectively to media content, they may choose to see messages that are the most congenial and least hostile to their positions. When exposure to media content decreases because of increased hostile media perception, the appraisal of such content on oneself and others was less pronounced.

In our study, respondents perceived the polls in the 2010 midterm elections as hostile to candidates of a party they support. Hence, they reduced the level of exposure to these polls viewed as undesirable, a sort of selective exposure strategy to avoid what they don't like to hear in the polls. Conversely, the more they see these polls, the more they 
reacted against them, which resulted in tuning out. The less exposure, the less the perceived impact of the polls on oneself and others. As the study of Coe et al. (2008) shows, when exposed to messages consistent with their own political views, people are more likely to make positive judgment such as finding the content interesting and informative. Gunther and Thorson (1992) suggest that positively viewed messages will lead to reverse third-person perception.

Taken together, the findings of our study suggest that exposure needs to be considered a critical mediator in examining audience perceptions of media bias and inference about media influence. Selective exposure theory (Zillmann and Bryant 1985), which proposes that people prefer to exposure themselves to media content that supports their positions, should be particularly insightful. For example, Stroud (2007) reported that politics as a topic is more likely to inspire selective exposure. To understand the influence of an increasingly partisan media on a divided electrorate, future research should investigate the nature and effect of selective exposure on perceptions of media bias and judgments of its impact using lab experiments to control for the different types of media polls.

Theoretically, becasue past studies failed to illuminate how the third-person effect and hostile media phenomenon are related when such antecedents as exposure and media attention are taken into account, the theretical path model we build fills a gap in the literature. We used polls in the 2010 midterm elections in a predominantly Republican state as the context. This context was carefully chosen because voters tend to pay less attention to off-year elections as compared to the media-hyped presidential elections. Our proposed model received strong support; it highlights the mediating role of exposure in assessing the influence of the hostile media effect on the third-person effect. Our model also indicates that exposure to election polls was related to support for restriction of election polls both directly and indirectly, being mediated by perceived effects on self and perceived effects on others. These findings suggest that exposure to election polls predicts perceived effects on self and others, which in turn predict support for restriction of election polls. These are theoretically important findings because they help advance third-person effect research by demonstrating that exposure is an important variable that predicts and precedes perceived effects and support for media restriction.Our proposed model thus makes a contribution to media effects research.

Fumdamentally, the hostile media phenomenon is a cognitive mechanism behind the postmodern notion that "believing is seeing." Whether election polls are fair and unbiased is in the eyes of the behold. The pheromone of political polarization in America (Baldassarri \& Gelman, 2008) suggests that ideological polarization has increased dramatically among the mass public as well as among political elites. Further, Abramowitz and Saunders (2008) reported the deepest divisions among the most interested, informed, and active citizens. These studies offer plausible explainations for the findings reported in this study.

One important implication of our findings is that the hostile media effect may help explain why the third-person effect occurs. As a cognitive mechanism, the more media messages are perceived as leaning favorably toward their opponents, the more undesirable the message. Message undesirability leads to third-person perception-the more undesirable the message, the greater the self-other perceptual gap.

Practically, our findings may provide some insights for campaign planners. Because people tend to avoid media which they preceived to be hostile to them and stick to media that they feel friendly. This tendency of selective expsorue suggests that election messages targettting partisan voters should be placed on media channles or platforms that attratct partisans. On the other hand, messages targetting general voters, not partisans, should consider buying media space across the media specture.

A limition of our study comes from sampling exclusively of college studetns. Previous research (Paul et al., 2000) suggests that the third-person perceptual bias is larger in college student samples than in non-student sample becasue college studetents tend to see themslves as smarter. Therefore, future research should test the model using a sample drown from the general public.

\section{CONFLICT OF INTEREST}

The authors confirm that this article content has no conflicts of interest.

\section{ACKNOWLEDGEMENT}

Declared none.

\section{REFERENCES}

Abramowitz, A., \& Saunders, K. (2008). Is polarization a myth? The Journal of Politics, 70 (2), 542-555.

Arceneaux, K., Johnson, M., \& Murphy, C. (2010). Hostile media judgments, polarized political communication, and selective exposure. Working paper, Temple University: USA.

Arpan, L.M., Bae, B., Chen Y., \& Greene, G. (2009). Consumption and partisanship as predictors of the Hostile Media Effect in late night political comedies and traditional news. Paper presented at the International Communication Association conference, Chicago, IL. (May).

Arpan, L., \& Raney, A. (2003). An experimental investigation of news source and the hostile media effect. Journalism and Mass Communication Quarterly, 80(2), 265-281.

Baldassarri, D. \& Gelman, A. (2008). Partisans without constraint: Political polarization and trends in American public opinion. American Journal of Sociology, 114 (2), 408-446

Coe, K., Tewksbury, D., Bond, B.J., Drogos, K.L.,Porter, R.W., Yahn, A., \& Zhang, Y. (2008). Hostile news: Partisan use and perceptions of cable news programming. Journal of Communication, 58, 201-219.

Chia, S. C., Lu, K., \& McLeod, D. M. (2004). Sex, lies, and video compact disc: A case study on third-person perception and motivations for media censorship. Communication Research, 31(1), 109-130.

Chia, S.C., Yong, S., Wong, D., \& Koh, W. (2007). Personal bias or government bias? Testing the hostile media effect in a regulated press system. International Journal of Public Opinion Research, 19(3), 313-330.

Dalton, R., Beck, P., \& Huckfeldt, R. (1998). Partisan cues and the media: Information flows in the 1992 presidential election. American Political Science Review, 92(1), 111-126.

Davison, W.P. (1983). The third-person effect in communication. Public Opinion Quarterly, 47(1), 1-15.

de Vreese, C.H., \& Semetko, H.A. (2002). Public perception of polls and support for restrictions on the publication of polls: Denmark's 2000 euro referendum. International Journal of Public Opinion Research, 14(4), 367-390.

Duck, J.M., Terry, D.J., \& Hogg, M.A. (1995). The perceived influence of AIDS advertising: Third-person effects in the context of positive 
media content. Basic and Applied Social Psychology, 17(3), 305325 .

Eveland, W.P., Nathanson, A., Detenber, B.H., \& McLeod, D.M. (1999). Rethinking the social distance corollary: Perceived likelihood of exposure and third-person perception. Communication Research, 26(3), 275-302.

Eveland, W.P. \& Shah, D.V. (2003). The impact of individual and interpersonal factors on perceived news media bias. Political Psychology, 24 (1), 101-117.

Gallup. (2010). 2010 midterm election daily polls. Retrieved on March 2, 2011, from http://www.gallup.com/poll/127439/election-2010-keyindicators.aspx.

Giner-Sorolla, R., \& Chaiken, S. (1994). The causes of hostile media judgment. Journal of Experimental Social Psychology, 30(2), 165180 .

Gunther, A.C. (1991). What we think others think: Cause and consequence in the third-person. Communication Research, 18(3), 335-372.

Gunther, A.C., \& Chia, S.C. (2001). Predicting pluralistic ignorance: The hostile media perception and its consequences. Journalism \& Mass Communication Quarterly, 78(4), 688-701.

Gunther, A.C., \& Christen, C.T. (2002). Projection or persuasive press? Contrary effects of personal opinion and perceived news coverage on estimates of public opinion. Journal of Communication, 52, 177-195

Gunther, A. C., \& Schmitt, K. (2004). Mapping boundaries of the hostile media effect. Journal of Communication, 54(1), 55-70.

Gunther, A.C., \& Storey, J. (2003). The influence of presumed influence. Journal of Communication, 53(2), 199-215.

Gunther, A.C., \& Thorson, E. (1992). Perceived persuasive effects of product commercials and public service announcements: Thirdperson effects in new domains. Communication Research, 19(5), 574-596.

Hoffner, C. \& Rehkoff, R. (2011). Young Voters' Responses to the 2004 U.S. Presidential Election: Social Identity, Perceived Media Influence, and Behavioral Outcomes Journal of Communication, 61(4), 732-57.

Johnson, T., \& Kaye, B. (1998). Cruising is believing? Comparing Internet and traditional sources on media credibility measures. Journalism \& Mass Communication Quarterly, 75, 325-340.

Lavrakas, P., Presser, S., Price, V., \& Traugott, M. (1998). Them but not me: The perceived impact of election polls. Paper presented to the annual meeting of the American Association for Public Opinion Research, St. Louis, MO, (May).

Lo, V. (2004). Selective credibility. Mass Communication Research, 80, 150.

Lo, V., \& Wei, R. (2002). Third-person effect, gender and pornography on the Internet. Journal of Broadcasting and Electronic Media, 46(1), 13-33.

Matheson, K., \& Dursun, S. (2001). Social identity precursors to the hostile media phenomenon: Partisan perceptions of coverage of the Bosnian conflict. Group Processes \& Intergroup Relations, 4(2), 116-125.

McLeod, D.M., Eveland, W.P., \& Nathanson, A.I. (1997). Support for censorship of violent and misogynic rap lyrics: An analysis of the third-person effect. Communication Research, 24(2), 153-175.

Mende, A. (2008). Testing the hostile media effect under selective exposure. Paper presented at the annual convention of the International Communication Association, Montreal, Quebec, Canada.
Pan, Z., Abisaid, J.L., Paek, H., Sun, Y., \& Houden, D. (2005). Exploring the perceptual gap in perceived effects of media reports of opinion polls. International Journal of Public Opinion Research, 18(3), 340-350.

Paul, B., Salwen, M.B., \& Dupagne, M. (2000). The third-person effect: A meta-analysis of the perceptual hypothesis. Mass Communication \& Society, 3(1), 57-85.

Perloff, R.M. (1989). Ego-involvement and the third-person effect of news: The impact of question order, contrast and knowledge. International Journal of Public Opinion Research, 8, 120-141.

Perloff, R.M. (2002). The third-person effect. In: Bryant, J. \& Zillman, D. (Eds.), Media Effects: Advances in Theory and Research (pp. 489506). Hillsdale, NJ: Lawrence Erlbaum Associates.

Price, V., Tewksbury, D., \& Huang, L. (1998). Third-person effects on publication of a Holocaust-denial advertisement. Journal of Communication, 48, 3-26.

Price, V., \& Stroud, N. (2005). Public attitudes toward polls: Evidence from the 2000 U.S. presidential election. International Journal of Public Opinion Research, 18(4), 393-421.

Rucinski, D., \& Salmon, C.T. (1990). The "other" as the vulnerable voter: A study of the third-person effect in the 1988 U. S. presidential campaign. International Journal of Public Opinion Research, 2(4), 345-368.

Salwen, M.B. (1998). Perceptions of media influence and support for censorship: The third-person effect in the 1996 presidential election. Communication Research, 25(3), 259-285.

Stroud, N. (2007). Media use and political predispositions: Revisiting the concept of selective exposure. Political Behavior, 30(3), 341-366.

Sun, Y., Pan, Z., \& Shen, L. (2008). Understanding the third-person perception: Evidence from a meta-analysis. Journal of Communication, 58(2), 280-300.

Sun, Y., Shen, L., \& Pan, Z. (2008). On the behavioral component of the third-person effect. Communication Research, 35(2), 257-278.

Tal-Or, N., Tsfati, Y., \& Gunther, A. (2009). The influence of presumed media influence: Origins and implications of the third-person perception. In: Robin, N. \& Olver, M. (Eds.), The Sage handbook of media processes and effects, (pp. 99-112). LA, CA: Sage.

Vallone, R.P., Ross, L., \& Lepper, M.R. (1985). The hostile media phenomenon: Biased perception and perceptions of media bias in coverage of the Beirut massacre. Journal of Personality and Social Psychology, 49(3), 577-585.

Wei, R., \& Lo, V. (2007). The third-person effects of political attack ads in the 2004 U. S. presidential election. Media Psychology, 9(2), 367388 .

Wei, R., Lo, V., \& Lu, H. (2008). Third-person effects of health news: Exposure, third-person effects and behavioral intentions. American Behavioral Scientist, 52(2), 261-277.

Wei, R., Lo, V., \& Lu, H. (2010). Examining the perceptual gap and behavioral intention in the perceived effects of polling news in the 2008 Taiwan presidential election. Communication Research, 37(5), 206-227.

Wei, R., Chia, S., \& Lo, H. (2011). Influences of the third-person effect and hostile media perception on voter attitudes toward polls in the 2008 U.S. presidential election. International Journal of Public Opinion Research, 23(2), 169-190.

Youn, S., Faber, R.J., \& Shah, D.V. (2000). Restricting gambling advertising and the third-person effect. Psychology and Marketing, 17(7), 633-649.

Zillmann, D., \& Bryant, J. (1985). Selective Exposure to Communication. Hillsdale, NJ: Lawrence Erlbaum. 